\title{
'When it comes to HIV, that's when you find out the genuinity of that love': The experience of disclosing a HIV+ status to an intimate partner
}

Charlotte Smith, Department of Psychology, Anglia Ruskin University, UK. Rachel Cook, Department of Psychology, Anglia Ruskin University, UK. Poul Rohleder, School of Psychology, University of East London, UK.

Accepted 21 December 2016 for publication in Journal of Health Psychology This article may not exactly replicate the final version published in the journal.

\begin{abstract}
Despite a medical discourse of the 'normalisation' of HIV, it remains a highly stigmatising condition, and makes the issue of disclosing one's HIV status particularly complex. This paper reports on the experience of 18 people living with HIV in the UK of disclosing their HIV + status in arguably their most important relationship, their intimate partnership. Five main themes arose: disclosure as the battlefield, preparing psychologically to disclose, disclosure as a test of the partner's love, disclosure as an opportunity for the partner to know them more deeply, and the renegotiation of the relationship narrative.
\end{abstract}




\section{INTRODUCTION}

Despite considerable advances in the medical treatment of HIV and AIDS, HIV remains a significant public health concern (UNAIDS, 2015). Although prevalence rates in many parts of the world have stabilized, and the rates of new infections have seen a decline, there are increasing epidemics in other parts of the world (such as Eastern Europe) (UNAIDS, 2015). The goal set by UNAIDS (2015) is to see that the number of new infections reduce significantly by 2030. It is hoped that new advances in medical treatments, such as pre-exposure prophylaxis (PrEP), will help facilitate the prevention of onwards transmission of HIV. However, the practicing of HIV disclosure and safe sex remain fundamental to HIV prevention efforts (Giannou et al, 2015; O’Connell, Reed \& Serovich, 2015).

HIV disclosure, particularly within an intimate partnership, constitutes a standalone HIV intervention. Within this context, the act of telling has proven effective in prompting safer sexual practices (e.g. condom use; Loubiere, Peretti-Watel, Boyer, Blanche, Abega \& Spire, 2009) and greater adherence to HIV medication (reducing infectiousness) (Pichon et al, 2015). Thus HIV disclosure is an important HIV prevention strategy. Pinkerton and Galletly (2007) produced a mathematical model which indicates that up to $59.2 \%$ of HIV transmissions could be avoided through practicing disclosure to a sexual partner. However, HIV disclosure is also a complex, interpersonal process that provides a multitude of social and psychological benefits. It has been found to facilitate access to formal and informal social and psychological support (Maman, van Rooyen \& Groves, 2014; Wohl et al, 2011), and plays a significant role in addressing HIV stigma 
by making the illness more visible (Paxton, 2002; WHO, 2000). Considering that stigma is now held as the major driver of the epidemic this is another major benefit of HIV disclosure (Brent, 2016).

Originally HIV disclosure was understood and investigated as a public health strategy, for preventing onwards transmission, and for facilitating access to support. With improved and effective medical treatment, people living with HIV are able to live a normal lifespan, and so disclosure has taken on a different emphasis in terms of entering and living in relationships throughout an individual's life. One could say HIV disclosure is part of revealing aspects of one's identity and according to one theoretical account, in turn an individual's social identity wholly informs their disclosure-related choices (Arnold, Rice, Flannery \& Rotheram-Borus, 2008). That is, it is believed that a person's cognitions regarding their social role and social identity come together to form a 'disclosure rule' (disclosure decision) (Arnold et al, 2008). Additionally, the medical advances of recent years have led to what some refer to as the 'normalisation' of HIV (Squire, 2013) where HIV can be considered just like any other chronic illness. This is translated into theoretical accounts such as the Disclosure Processes Model, which despite being heavily drawn on in the HIV disclosure literature, is fundamentally a generic (that is, non-disease-specific) model intended for application to a wide range of stigmatized health conditions (Chaudoir \& Fisher, 2010). Although disclosure of certain medical and sexual health conditions is challenging (Myers, Buhi, Marhefka, Daley \& Dedrick, 2016), it would be simplistic to assume that disclosure of one's HIV status is just like disclosing any other chronic condition. HIV stigma has always been, and remains, a highly significant issue that evokes significant fear in others (Adeoye- 
Agboola, Evans, Hewson, \& Pappas, 2016; Bird \& Voisin, 2010; Skinta, Brandrett, Schneck, Wells \& Dilley, 2014). Cantisano, Rime and Munoz-Sastre (2012) reported lower disclosure rates from individuals disclosing HIV, compared to those disclosing another (non-stigmatized) condition (cancer or diabetes).

A limited number of qualitative studies support that disclosure of a HIV + status is markedly complex due to the issue of HIV stigma. Flowers and Davis (2012) demonstrated the pervasive role of HIV stigma throughout the longitudinal disclosure processes of $16 \mathrm{HIV}+$ gay men. HIV stigma was found to not only influence disclosure-related decisions and behaviors, but the fundamental experience of disclosing (also see Evangeli \& Wroe, 2016). Interview research has further revealed that to an extent disclosure serves as a form of stigma identity management (Murphy, Hevey, O’Dea, Rathaille \& Mulcahy, 2015; Owuor, Locke, Heyman \& Clifton, 2015). With HIV being loaded with connotations of being 'dirty', deviant, immoral and socially rejected (Rohleder, McDermott \& Cook, in press), disclosure is becoming a way of managing this HIV+ social identity (Murhphy et al, 2015; Skinta et al, 2014).

In addition to HIV disclosure involving disease-specific complexities, it also has a highly complex interpersonal component, which has largely gone ignored. This is inappropriate when acknowledging that the wider self-disclosure literature regards disclosure as an act of intimacy, that is central to developing and maintaining social relationships (Laurenceau, Barrett, \& Pietromonaco, 1998). One theoretical model has incorporated an interpersonal component into the account; the Disclosure and Types of Social Relationships Model (Bairan, Taylor, Blake, Akers, 
Sowell, \& Mendiola, 2007) holds that disclosure is much more likely to occur in close committed relationships, than casual ones. However, empirical research on the interpersonal aspects of HIV disclosure remain relatively unexplored. Interpersonal dynamics in HIV disclosure have begun to emerge in a small number of studies (Dima, Stutterheim, Lyimo \& de Bruin, 2014, BLINDED, 2016). These studies have recently begun to highlight that the process of disclosure does not occur in a uniform manner across all relationship contexts. Rather, marked differences in the process have been reported as a function of the relationship in which it is taking place (e.g. to an intimate partner, colleague, family) and according to the qualities of the relationship (BLINDED, 2016). Differences in the process according to the relationship include the reasons for and against reaching the disclosure decision (Derlega, Winstead, Greene, Serovich \& Elwood, 2002), the barriers and facilitators to implementing the decision (Derlega et al, 2002), and the resulting consequences. At present however, the dearth of literature that has specified the relationship context has mostly confined disclosure to casual sexual partners, and gathered accounts from predominantly white men who have sex with men (MSM) in the context of the gay scene (e.g. Flowers et al, 2012; Skinta et al, 2014).

Importantly, disclosure within a stable intimate partnership not only acts as a robust evidencebased HIV preventative measure (as emphasized in the former) but also aids understanding in how to support PLWH to negotiate stable, long-term intimate partnerships as part of living fully with the virus. With this need in mind, this paper reports on a qualitative study in which the aim was to provide a detailed and nuanced understanding of the experience of disclosing a HIV+ status specific to a stable intimate partner. 


\section{METHOD}

\section{Participants}

Eighteen PLWH who had experienced telling an intimate partner about their HIV+ status took part. They were recruited via prominent HIV support organisations across England and Scotland. The sample included core groups affected by HIV across the UK (Public Health England, 2014). Out of the 18 that took part, four self-identified as white-British men who have sex with men (MSM), three identified as black-African heterosexual men, nine identified as black-African heterosexual women, one as a white heterosexual man and 1 as a mixed-race heterosexual woman. The age of participants ranged from 21 to 61 years (with a mean age of 42).

\section{Method of data collection}

Data was collected by means of in-depth semi-structured interviews conducted by the first author. Each participant was provided with the option of completing the interview either face-to-face or over the telephone. Telephone interviews are increasingly being used in qualitative research with the advent of ever improving online communication (Lyons, 2015). This additional long-distance data collection method allowed us to collect data from a geographically diverse sample (Jutel \& Banister, 2013). Evidently, this was effective; the final sample were located in Cambridge, London, Scotland, Manchester, Norfolk and West Midlands. 
On average, interviews lasted about one hour, with no significant difference between the duration of phone and face-to-face interviews. Eleven were completed face-to-face, with the remaining seven being completed over the phone. An interview schedule was loosely used to guide the topics being discussed. These topics included previous experiences of disclosing a HIV + status, disclosure to an intimate partner in particular, and perceived impacts of these disclosure experiences. All provided informed consent prior to being interviewed. Ethical approval was obtained from the Faculty of Research Ethics Committee at [University]. A small monetary token of gratitude was offered for taking part.

Method of data analysis

The data was transcribed and analysed by the study team. Thematic analysis was drawn on to analyse the data (Braun, Clarke \& Terry, 2015). The analytic process was as follows: themes that ran across the transcripts were initially identified by the first author using both an inductive and deductive approach; some were partly informed by the focus of the research questions asked, and some solely emerged from the transcripts. The themes were presented and discussed with the wider study team. The themes resulting from this process were further developed and refined by the study team, through a reiterative process of returning to the data. 


\section{RESULTS}

The analysis of the data revealed 6 overarching themes: disclosure as a psychological battle; preparing psychologically to disclose; disclosure as a test of the partner's love; disclosure as an opportunity for the partner to know them more deeply; and the renegotiation of the relationship narrative. For the sake of clarity each of these themes will be discussed in turn below, however as will become clear these themes are interdependent. Table 1 presents a summary of the key themes and sub-themes.

INSERT TABLE HERE

\section{Disclosure as a psychological battle}

Many participants described disclosure to an intimate partner as a challenging and difficult aspect of living with the condition. Participants spoke of disclosure presenting 'a big problem', a 'struggle' and that it is 'not an easy thing' to do. Additionally, the consideration of whether to disclose was associated with a particular affective experience, of angst and 'worry'.

Disclosure to an intimate partner was experienced as a tough psychological battle. Many participants described having worked hard over a protracted period of time to find the courage and strength to decide to tell: 
R: no I took me-it took me err like err-I was just when I see can I tell her. How is she gonna react. Took me like err a month. A month yeah. Until I decided to tell her-balancing it up. So I had to' (R: 14, black-African heterosexual male)

One participant explicitly referred to the process of reaching the decision as a 'battle'. A further participant reported that they 'battled' with it 'for some time, for almost six months'. Looking back on the process, participants described this phase as being a 'really long drawn out process'. One participant explained:

'so if I'm to tell somebody...this is not something that will take a month or 2 or 3 months' (R: 15, black-African heterosexual male)

\section{Preparing psychologically to disclose}

Participants did not present disclosure as something that occurred momentarily. Rather, it was presented as occurring after considerable preparation. Each participant described ways in which they increased their preparedness to enact the decision. Three common preparatory strategies were identified in participant accounts: gaining mastery through HIV education; testing the waters; and imagining various scenarios.

Mastery through HIV education

One way in which some participants prepared to disclose was through seeking to increase their knowledge of HIV from a medical perspective. This aided participant's in psychologically preparing for the event 
through becoming 'armed' with knowledge and understanding. One woman captures this strategy in a quote below:

'I: so how did you manage the issue of telling people?

R: what I did was [pause] I got so interested into it as a subject. Yeah I thought oh. I think for me to really really engage into this thing I must know much about this. So what I did, those days they were offering a diploma in HIV at-at-at [institution]. So I-so I enrolled and then I went there and then I learned the part of knowledge of it and all sorts of things about it. About HIV. And then with that you get so empowered that it becomes like oh well one of those things which happens. I've got to lift my head up high here' (R: 2, blackAfrican heterosexual female)

Similarly, a male participant responded:

It wasn't until that I read up on it and researched it and did all sorts to like stop myself being so ignorant. That I- that I wasn 't a threat to anyone and no one's you know gonna be, catch anything by by shaking my hands or giving me a hug or anything like that That's the kind of knowledge I don't think a lot of people have' (R: 10, white-British MSM, male)

As these quotes illustrate, obtaining knowledge about HIV helped those who drew on this strategy to increase their self-esteem, and enabled them to approach disclosure from an empowered position. This assisted them in approaching the issue of disclosure with their partner. As one participant phrased it, after becoming educated about HIV, they were able to approach disclosure with their 'head up high'.

Testing the waters

A second strategy involved 'testing the waters'. This occurred via two main ways. Firstly, some disclosers enacted a 'softer' disclosure as a precursor to the 'full' admission of their HIV+ status. This earlier, milder 
disclosure acted to 'flag up' with the partner that there was something yet to be known about their identity that was negative and undesirable.

'when he phoned me to say oh this is what I'm thinking about you I said [pause] w-w-why are you thinking of you know like that. Do you know, you know, the type of person that I am' [R: 4, black-African heterosexual female)

After dropping a hint of the disclosure to follow, the partner's reaction was observed. A positive reaction was taken as reaffirming their decision to tell, and encouraged them to continue along in the process.

yeah because then you know, you're gauging the perception... and if you feel that it's compassionate and understanding reaction umm and then you disclose that, then you see...in one way it's a dance. It's like a psychology dance to find out where, what is the opinion of the other person or where they are on the system. Cause you know where you are and it's trying to sort of like umm [pause] it's like holding a channel of communication, it's like trying to stop your phone lines of contact, and you know, have you got my signal [laughs]' (R: 1, white-British MSM, male)

The second main way in which disclosers 'tested the waters' involved gathering the partner's attitudes towards PLWH more generally.

'play dumb first time around and say the other person say well do you wanna use a condoms, like have you used before, is that a good idea, could you catch things by that, you don't want these things, and pretend you don't know and stuff and see what their reaction is....you're able to gauge the other person's response or their level by what they say...yeah because then you know, you're gauging the perception' (R: 1, white-British MSM, male)

Similarly, a female participant recalled how she drew on the first strategy when testing the waters with her partner: 
'I was in a relationship this one time and I was contemplating telling this guy. I said okay well let's just find a way of telling about HIV see how he react. Then I will know how he will react to it. So I just told him look where I work with a person with HIV I will work they just find somebody they has HIV and I will work for the person and the first thing he said was like please...you have to be careful. You can't. And you come to this house to eat. No way. That was even that I never expected that. It was so upsetting, no way. I can 't- I can't, I can't [disclose]...so you know what, I just didn't tell him... when you go out with somebody as I've said you ask them a question about $H I V$. No relating to it yourself and see the way they will react. If they react in a very bad way, negative way, know that no, you know, so. I will say use my patterns of telling people and I will interrogate and see their reactions and everything' (R: 5, black-African heterosexual female)

This worked to provide a clue of the attributes that their partner may transfer onto them upon learning of their HIV.

Both of these strategies worked to provide the discloser with an opportunity to reassess the suitability of their disclosure decision, through gauging how their partner might most likely react before enacting the full disclosure.

\section{Imagining scenarios}

Another component in psychologically preparing for the disclosure involved imagining the various disclosure scenarios that could arise upon telling the partner, and how each of these could be managed by the discloser.

'the risk is, which is one I do see happening occasionally, you and I the next thing is we rented a flat together and one day you turn round to me you say [name] what are these bottles of pills here [pause]...I think if you-if you put yourself into this position I suspect you would then turn round and think what else hasn't he told me. What other lies are there? And slowly however you deal with it. 
Slowly the relationship is going to crumble...it's all-it's rather life a a piece of fruit, it's gonna rot from the inside out' (R: 16, whiteBritish MSM, male)

To aid the discloser in predicting how the event might unfold, they reflected on how they would have responded to a disclosure, if placed in their partner's 'shoes'.

'I always switch positions to say if that was me being in his shoes how was I gonna take it. Was I gonna stand' (R: 3, black-African heterosexual female)

'I thought well I'd be disgusted. I wouldn't want to be friends-I wouldn't want to touch or you know, at that point' (R: 10, whiteBritish MSM, male)

\section{Disclosure as a test of the partner's love}

Within the intimate partner context, participants spoke about how disclosure marked a defining moment in their relationship. For most, it became an opportunity to test their partner's love, and commitment to the relationship.

'I: did you think there were- would be any advantages to you telling him...?

$R:$ the advantages would be if he really loved me then he will stay. If he doesn't then goodbye' (R: 2, black-African heterosexual female)

'if you love somebody, if somebody really loves you, when it comes to HIV, that's when you find out the genuinity of that love... at the end of the day, the love that is between the 2 of us is what made us' (R: 3, black-African heterosexual female)

The disclosure event was understood as either 'making or breaking' the relationship. Participants seemed to frame this aspect of disclosure from a position of empowerment- in that they were in a sense taking control 
of the destiny of the relationship. If the partner could not cope with the reality of HIV, then they were perceived as not good enough. Disclosure was presented as an instrument to test if 'they're going to care about you genuine'.

'tell someone because if they reject you for it then they're not worthy it really. You know, I mean if they want to be with you they will be fine with it. And they'll get over their fears. And they'll see that you're worth the risk...so it's that kind of-you're not really losing anything because I think if someone would have an issue with you being HIV positive the relationship wouldn't last anyway. Because you know, if they don't see you as worth more than that [pause] that kind of thing. So the guy that I told last year who wasn't interested because of it it was a bit more of a well you know if we had got together you would have found something else that you thought I wasn't worth putting up for (R: 10, white-British MSM, male)

'so either you accept me for what I am, rather than accept me for what I'm not' (R:1, white-British MSM, male)

\section{Disclosure as an opportunity for the partner to know them more deeply}

For many participants, disclosure concurrently signified a point of vulnerability in the relationship. Some participants explained this sense of vulnerability through presenting disclosure as an act of giving of one's whole self to the partner, revealing a 'biggest secret' that by default they kept hidden. To this end, disclosure enabled them to share more of themselves, and thereby signified an act of deep (emotional) intimacy.

'cause that's the biggest secret that one will ever have. And it's the biggest secret one will disclose to anybody whom she don't like. You know, won't tell somebody you don't like about it' (R: 3, black-African heterosexual male)

I'm HIV which is a big part of me. So I think it's important that a partner sees all of you. Not just the little bits of you. You know, like little bit there, little bit here. You know, it's only they can know that, only they can know that, only that can know' (R: 12, mixed whiteother, heterosexual female) 
However, at the same token, disclosers were aware that upon disclosing they placed their relationship at the mercy of their partner, and were aware of the risk of being rejected:

'really, I'm the vulnerable person. I'm the vulnerable partner' (R: 1 , white-British MSM, male)

'well they can reject you, they can judge you, they can disown you, they can take the mickey out of you, they can make remarks about you' (R: 12, mixed white-other, heterosexual female)

\section{Renegotiation of the relationship narrative}

Upon the introduction of HIV into the relationship, it was clear that in moving forward with the long-term relationship it was necessary for the relationship narrative to undergo a period of renegotiation. This was presented by the discloser as a joint activity, and occurred through two main avenues.

Constructing a happy ending: 'You, me, and the disease'

Firstly, according to the discloser, the partnership worked together to co-construct a type of story where the HIV played a role in the couple's happy ending. Often, participants concluded that the communication of their HIV+ status had ultimately made the couple closer, more harmonious and 'as strong as ever'.

'and you know, he he he he's very supportive. Cause last year when I, cause I had this same operation again last year, but then this thing keeps coming back so that's why they want to find why it keeps coming back. So last year when I had an operation he was there. He came and he was with me in the hospital. And he stayed with me for a couple of days. Helping with the cooking, and the ironing and stuff' (R: 4, black-African heterosexual female)

'if you disclose intimately to a partner it can actually strengthen the relationship. And that- that's a very positive thing.... and also it it's umm it gives trust and honesty to the relationship' (R: 1, white-British MSM, male) 
A significant number of participants also associated the disclosure event with an increase in commitment within the relationship.

'after I told him he asked if I wanted to be in a relationship with him....I think it just meant that he had no issues whatsoever... and he never had any issues with it' (R: 10, white-British MSM, male)

Cause the moment I told him he just told me that he honestly was very pleased to hear me disclosing about this HIV. Because he's never heard of any woman, even a man, disclosing their HIV status. And that thing encouraged him to say this is an honest wife. We went on to have a wedding. I went back to Africa had a wedding. Now we've got 2 children...we got 2 children and they, this one is going to be 5 in March. The second one is going to be 2 next month' (R: 7, black-African heterosexual female)

'We're the same'

In order for the relationship to move forward participants reported that it was important that they continued with this period of renegotiating the relationship narrative, specifically to focus on the similarities the partners shared, mostly likely as a way of dealing with the 'difference' that HIV created within the relationship. This often involved drawing on similarities between health concerns that their partner may have and their HIV+ condition, emphasising that they were both dealing with health issues.

'I don't know his status...he had an operation in the-in his head... an aneurism yeah. So it's like he's a weakling himself aswell' (R: 4, black-African heterosexual female)

'and then what he told me that even he has high blood pressure. He's taking medication for life. So it's the same thing. So if- that time I stopped taking TB tablets now they put me on medication for the viral load. But he told me well we are just the same is that our illnesses are different. I'm taking high blood pressure for life and you are taking this for life. You don't have to fear, you know. So that gave me some peace within me. And then the relationship continued' (R: 6, black-African heterosexual female) 


\section{Discussion}

Although there has been a number of studies looking at psychosocial issues related to HIV disclosure, relatively less attention has been given to the psychological and interpersonal experiences of disclosing one's HIV status to one's intimate partner, in the context of HIV being considered a chronic, manageable condition. In contrast to the notion of the 'normalisation' of HIV (Squire, 2013), the results indicate the saliency of HIV stigma. Despite parallels being drawn between HIV and other manageable chronic health conditions, it is clear from these findings that this HIV stigma, born from fear of HIV, persists in isolating HIV from other conditions (e.g. hepatitis C, herpes). The consequence of this is evident; participants experienced disclosing their HIV status as stressful, demanding, and a protracted psychological battle entailing careful preparatory work

The serious nature of HIV disclosure in this highly intimate context, born from the pronounced stigma and fear associated with HIV meant that idiosyncrasies arose in the perceptions and meanings of disclosing within an intimate relationship. Disclosure was perceived here as a critical, definitive act with regards the seriousness and legitimacy of the relationship, marking the beginning of an increasingly meaningful relationship, or as a test of the relationship. For the participants, disclosure was also regarded as important for being a 'good partner'; in terms of setting the foundations of the relationship and proceeding with the relationship in the future. But it also came with the risk of becoming an unacceptable partner, and consequently presented the threat of termination of the relationship, in which the discloser was invested in, emotionally and in terms of time. These findings stand in contrast to the experience of disclosing to a casual sexual partner, in which the main salient 
issues are oriented towards maintaining an intact social identity (in the context of the wider sexual network in which both casual partners are situated) and managing the threat of transmission posed by engaging in sexual intimacy (i.e. through denying any risk exists) (see Flowers et al, 2012; Murphy et al, 2015).

These findings reiterated that disclosure is 'complex and multifaceted' (Eustace \& Ilagan, 2010, p. 2096) despite the evident 'normalisation' of HIV (Squire, 2013). They capture the complexities of disclosing specifically to an intimate partner. In parts, participants used it to 'work for them', and in another sense, it was experienced as a necessary obligation which forced them into a vulnerable position. It seems clear that disclosers actively engaged with, shaped, interpreted, and experimented during the process, by imagining different scenarios and trying to ascertain what kind of response they might receive from their partner and acting out different kinds of disclosure from hints to outright disclosure. This supports previous findings observed by Flowers et al (2012) and Greene et al (2008). Beyond the initial disclosure act, disclosure became an activity that both partners jointly engaged in; the partnership co-constructed a relationship story that incorporated HIV and became centred on the partners' similarities. This is far from the sort of disclosure model that considers disclosure as onedimensional, and as a set of clear-cut defined stages (e.g. Bairan et al, 2007).

Despite finding that disclosure can serve the discloser in various domains of their life (e.g. deepening their relationships), these findings identify that in the earlier stages in the process, disclosure is experienced as aversive, difficult and intense. This property of HIV disclosure shares similarities to disclosing other stigmatized health conditions such as hepatitis C (Dunne \& Quayle, 2002), genital herpes and the human papilloma virus (HPV) (Newton \& McCabe, 2008). It has previously been stated 
that the transformation of HIV from a terminal to a chronic illness 'may mean that...disclosure has become easier' (Denis, 2014, p. 283), and so could be incorporated with disclosure research on the conditions named above. These findings, along with those by Gillar and Roark (2014) clearly indicate that this is not the case- facing the task of enacting a HIV disclosure presents as a very stressful problem for PLWH, presenting unique complexities resulting from its highly stigmatising nature. On a positive note however, the reported experiences following disclosure were positive (also see Rotzinger et al, 2016 and Sofolahan-Oladeinde \& Airhihenbuwa, 2014), and led to feelings of empowerment and increased relatedness to the partner. This increased relatedness to the partner was originally identified by Sofolahan-Oladeinde \& Airhihenbuwa (2014) following HIV disclosure by women to their partner during family planning, pregnancy and childbirth. From these findings it appears that a disclosure intervention that helps PLWH to negotiate the early decision-making phase of disclosure, so as to make it a less aversive experience holds great promise in aiding psychological adjustment to living with the condition (Rodkjaer, Sodemann, Ostergaard \& Lomborg, 2011).

Within the intimate partner context at least, respondent accounts indicate that beyond this point the implications of the disclosure for the relationship are generally negotiated by the partners. In the wider health literature, this process in which the partners work together on their relationship upon the uncovering of a health condition is referred to as 'dyadic coping' Traa, De Vires, Bodenmann, \& Oudsten, 2014. Dyadic coping in the current sample was aided by two particular strategies; these are working in partnership to construct a happy ending, which involved negotiating the HIV+ status into the relationship, and working as a dyad to emphasize their similarities, in the face of this significant difference (serodiscordance). Efforts in the neighbouring cancer illness literature have been focused towards developing interventions to enhance dyadic coping, upon finding that couples negotiating this 
health condition find it difficult to jointly cope (Manne \& Badr, 2008). The current seemingly effective strategies adopted by the current sample could potentially be used to aid dyadic coping in the context of other health conditions such as cancer, where deficits in this relational coping process have been shown (see Traa et al, 2014).

This study has some limitations. Namely, although the sample largely represented the epidemiology of HIV infections, it is possible that it was influenced by self-selection bias. That is, because it invited PLWH to come forward to talk in-depth about their experiences of intimate partner HIV disclosure, it is possible that only those that had a positive experience and outcome came forward and consented onto the study. Future research could reduce this possibility of self-selection bias by adopting a systematic sampling technique during recruitment (Sim \& Wright, 2000) (i.e. inviting every $\mathrm{n}^{\text {th }}$ number to participate in HIV clinics). Furthermore, the sample size does not permit us to generalize to the wider population. However, the strength of qualitative explorations is to give insights into personal experiences that are theoretically transferable to others in similar contexts and situations.

What this study does show, is that HIV may be considered by many as just another chronic condition (similar to diabetes, MS etc.), but HIV stigma continues to set this disease apart (Cantisano et al, 2012). The HIV disclosure process is fraught with disease-specific (Cantisano et al, 2012) and relationshipspecific (Dima et al, 2013) complexities, many of which are rooted in HIV stigma, and the subsequent need to manage a stigmatised identity. The end result is that disclosure of a HIV+ status remains psychologically difficult and interpersonally risky. In an age of austerity, many support services to people living with HIV are being cut in the UK, partly framed by the 'normalization' of HIV argument. However, it is clear that people living with HIV continue to require considerable 
support in adjusting to the unique complexities of living with this condition, and in particular, in relation to negotiating their HIV identity and close relationships (Conserve, Groves \& Maman, 2015).

Table 1

\begin{tabular}{l|l}
\hline Theme 1 & $\begin{array}{l}\text { Disclosure as the battlefield, and the decision as a psychological battle } \\
\text { Preparing psychologically to disclose }\end{array}$ \\
$\begin{array}{ll}\text { Subtheme 1: Mastery through HIV education } \\
\text { Subtheme 2: Testing the waters } \\
\text { Subtheme 3: Imagining scenarios } \\
\text { Theme } 3\end{array}$ & $\begin{array}{l}\text { Disclosure as a test of the partner's love } \\
\text { Disclosure as an opportunity for the partner to know them more deeply } \\
\text { Theme } 4\end{array}$ \\
Theme 5 the renegotiation of the relationship narrative Subtheme 1: Constructing a happy ending: \\
'You, me and the disease' \\
Subtheme 2: 'We're the same'
\end{tabular}

Table 1. An overview of the themes reported in this study (including subthemes) 


\section{References}

Adeoye-Agboola, D.I., Evans, H., Hewson, D., \& Pappas, Y. (2016). Factors influencing HIV disclosure among people living with HIV/AIDS in Nigeria: a systematic review using narrative synthesis and metaanalysis. Public Health, 136, 13-28. doi: 10.1016/j.puhe.2016.02.021

Arnold, E.M., Rice, E., Flannery, D., \& Rotheram-Borus, M.J. (2008). HIV disclosure among adults living with HIV. AIDS Care, 20(1), 80-92. doi: 10.1080/09540120701449138

Bairan, A., Taylor, G.A., Blake, B.J., Akers, T., Sowell, R., \& Mendiola, R. (2007). A model of HIV disclosure: disclosure and types of social relationships. Journal of the American Association of Nurse Practitioners, 19(5), 242-50. doi: 10.1111/j.1745-7599.2007.00221.x

Brent, R.J. (2016). The value of reducing HIV stigma. Social Science \& Medicine, 151, 233-240.

Bird, J.P., Voisin, D.R. (2010). A conceptual model of HIV disclosure in casual sexual encounters among men who have sex with men. Journal of Health Psychology, 16(2), 365-73. doi: $10.1177 / 1359105310379064$

Braun, V., Clarke, V., \& Terry, G. (2015). Thematic analysis. In P. Rohleder \& A. Lyons (Eds.), Qualitative research in clinical and health psychology (95-113). Basingstoke: Palgrave Macmillan.

Cantisano, N., Rime, B., \& Munoz-Sastre, M.T. (2012). The social sharing of emotions in HIV/AIDS: A comparative study of HIV/AIDS, diabetic and cancer patients. Journal of Health Psychology, 18(10), 1255-67, doi: 10.1177/1359105312462436

Chaudoir, S.R., \& Fisher, J.D. (2010). The disclosure processes model: Understanding disclosure decision making and postdisclosure outcomes among people living with a concealable stigmatized identity. Psychological Bulletin, 136(2), 236-256. doi: 10.1037/a0018193

Chenneville, T., Lynn, V., Peacock, B., Turner, D.A., \& Marhefka, L. (2015). Disclosure of HIV status among female youth with HIV. Ethics \& Behavior, 25(4).

Conserve, D.F., Groves, A.K., \& Maman, S. (2015). Effectiveness of interventions promoting HIV serostatus disclosure to sexual partners: A systematic review. AIDS \& Behavior, 19, 1763-72. doi: $10.1007 / \mathrm{s} 10461-015-1006-1$

Derlega, V.J., Winstead, B.A., Greene, K., Serovich, J., \& Elwood, W.N. (2002). Perceived HIV-related stigma and HIV disclosure to relationship partners after finding out about the seropositive diagnosis. Journal of Health Psychology, 7(4), 415-32. doi: 10.1177/1359105302007004330

Denis, P. (2014). New patterns of disclosure: how HIV-positive support group members from kwazulunatal speak of their status in oral narratives. Medical History, 58(2), 278- 297. doi: 10.1017/mdh.2014.23

Dima, A.L., Stutterheim, S.E.S., Lyimo, R., \& de Bruin, M. (2014). Advancing methodology in the study of HIV status disclosure: The importance of considering disclosure target and intent. Social Science \& Medicine, 108, 166-74. doi: 10.1016/j.socscimed.2014.02.045 
Dunne, E.A., \& Quayle, E. (2002). Pattern and process in disclosure of health status by women with iatrogenically acquired hepatitis C. Journal of Health Psychology, 7(5), 565-582. doi:

$10.1177 / 1359105302007005676$.

Eustace, R.W., Ilagan, P.R. (2010). HIV disclosure among HIV positive individuals: a concept analysis. Journal of Advanced Nursing, 66(9), 2094-103. doi: 10.1111/j.1365-2648.2010.05354.x

Flowers, P., \& Davis, M. M. (2012). Understanding the biopsychosocial aspects of HIV disclosure amongst HIV-positive gay men in Scotland. Journal of Health Psychology,18(5), 711-24. doi: $10.1177 / 1359105312454037$

Giannou, F.K., Tsiara, C.G., Nikopoulos, G.K., Talias, M., Benetou, V., Kantzanou...Hatzakis, A. (2015). Condom effectiveness in reducing heterosexual HIV transmission: a systematic review and metaanalysis of studies on HIV serodiscordant couples. Expert Review of Pharmacoeconomics \& Outcomes Research, 489-99. doi: 10.1586/14737167.2016.1102635

Gillard, A., \& Roark, M. F. (2013). Older adolescents' self-determined motivations to disclose their HIV status. Journal of Child and Family Studies, 22(5), 672-683. doi: 10.1007/s10826-012-9620-2

Greene, K., Derlega, V. J., Yep, G. A., \& Petronio, S. (2003). Privacy and Disclosure of HIV in Interpersonal Relationships: A Sourcebook for Researchers and Practitioners. London: Routledge.

Jutel, A., \& Banister, E. (2013). "I was pretty sure I had the 'flu": Qualitative description of confirmedinfluenza symptoms. Social Science \& Medicine, 99, 49-55. doi: 10.1016/j.socscimed.2013.10.011

Laurenceau, J.P., Barrett, L.F., \& Pietromonaco, P.R. (1998). Intimacy as an interpersonal process" The importance of self-disclosure, partner disclosure, and perceived partner responsiveness

in interpersonal exchanges. Journal of Personality and Social Psychology, 74(5), 1238-1251.

Loubiere, S., Peretti-Watel, P., Boyer, S., Blanche, J., Abega, S.C., \& Spire, B. (2009). HIV disclosure and unsafe sex among HIV-infected women in cameroon: results from the ANRS-EVAL study. Social Science \& Medicine, 69, 885-891. doi: 10.1016/j.socscimed.2009.05.044

Lyons, A. (2015). Approaches to collecting data. In P. Rohleder \& A. Lyons (Eds.), Qualitative research in clinical and health psychology (74-91). Basingstoke: Palgrave Macmillan.

Maman, S., van Rooyen, H., \& Groves, A.K. (2014). HIV status disclosure to families for social support in south africa. AIDS Care, 26(2), 226-32. doi: 10.1080/09540121.2013.819400

Manne, S.M., \& Badr, H. (2008). Intimacy and relationship processes in couples' psychosocial adaptation to cancer. Cancer, 112, 2541-55. doi: 10.1002/cncr.23450.

Murphy, P.J., Hevey, D., O’Dea, S., Rathaille, N.N., \& Mulcahy, F. (2015). Serostatus disclosure, stigma resistance, and identity management among HIV-positive gay men in Ireland. Qualitative Health Research, 26(11), 1459-72. doi: 10.1177/1049732315606687. 
Myers, J.L., Buhi, E.R., Marhefka, S., Daley, E., \& Dedrick, R. (2016). Associations between individual and relationship characteristics and genital herpes disclosure. Journal of Health Psychology, advanced online publication.

Newton, D.C., \& McCabe, M.P. (2008). Sexually transmitted infections. Impact on individuals and their relationships. Journal of Health Psychology, 13(7), 864-69. doi: 10.1177/1359105308095058

O'Connell, A.A., Reed, S.J., \& Serovich, J.A. (2015). The efficacy of serostatus disclosure for HIV transmission risk reduction. AIDS \& Behavior, 19(2), 283-90. doi: 10.1007/s10461-014-0848-2

Owuor, J.O.A., Locke, A., Heyman, B., \& Clifton, A. (2016). Concealment, communication and stigma: The perspectives of HIV-positive immigrant Black African men and their partners living in the United Kingdom. Journal of Health Psychology. Advance online publication.

Paxton, S. (2002). The paradox of public HIV disclosure. AIDS Care, 14(4), 559-567. doi: $10.1080 / 09540120208629674$

Pichon, L.C., Rossi, K.R., Ogg, S.A., Krull, L.J., \& Griffin, D.Y. (2015). Social support, stigma and disclosure: Examining the relationship with HIV medication adherence among ryan white Program clients in the Mid-South USA. International Journal of Environmental Research and Public Health, 12(6), 70737084. doi: 10.3390/ijerph120607073.

Pinkerton, S. D., \& Galletly, C. L. (2007). Reducing HIV transmission risk by increasing serostatus disclosure: a mathematical modelling analysis. AIDS and Behavior, 11(5), 698-705. doi: 10.1007/s10461006-9187-2.

Public Health England. (2014). HIV in the United Kingdom: 2014 Report. London: Author.

Rodkjaer, L., Sodemann, M., Ostergaard, L., \& Lomborg, K. (2011). Disclosure decisions: HIV positive persons coping with disease-related stressors. Qualitative Health Research, 21(9), 1249-1259. doi: $10.1177 / 1049732311405803$

Rohleder, P., McDermott, D., \& Cook, R. (in press). Experience of sexual self-esteem among men living with HIV. Journal of Health Psychology

Rotzinger, A., Locatelli, I., Raymermier, M., Amico, S., Bugnon, O., Cavassini, M., \& Shneider, M.P. (2016). Association of disclosure of HIV status with medication adherence. Patient Education and Counseling, 99, 1413-1420. doi: 10.1016/j.pec.2016.03.012

Sim, J., \& Wright, C. Research in Health Care: Concepts, Designs and Methods. Cheltenham: Nelson Thornes.

Skinta, M.D., Brandrett, B.D., Schneck, W.C., Wells, G., \& Dilley, J.W. (2014). Shame, self-acceptance and disclosure in the lives of gay men living with HIV: An interpretative phenomenological analysis approach. Psychology \& Health, 29(5), 583-97. doi: 10.1080/08870446.2013.871283 
Sofolahan-Oladeinde, Y., \& Airhihenbuwa, C.O. (2014). 'He doesn't love me less. He loves me more': perceptions of women living with HIV/ AIDS of partner support in childbearing decision-making. Health Care for Women International, 35, 937-53. doi: 10.1080/07399332.2014.920022

Squire, C. (2013). Living with HIV and ARVs. Three Letter Lives. Palgrave: London.

Traa, M.J., De Vires, J., Bodenmann, G., \& Oudsten, B.L.D. (2014). Dyadic coping and relationship functioning in couples coping with cancer: A systematic review. British Journal of Health Psychology, 20(1), 85-114. doi: 10.1111/bjhp.12094

UNAIDS. (2015). How AIDS Changed Everything. Switzerland: Author.

Wohl, A.R., Galvan, F.H., Myers, H.F., Garland, W., George, S., Witt, M.,...Lee, M.L. (2011). Do social support, stress, disclosure and stigma influence retention in HIV care for Latino and African American men who have sex with men and women? AIDS \& Behavior, 15(6), 1098-110. doi: 10.1007/s10461-0109833-6.

World Health Organization. (2000). Opening Up the AIDS Epidemic. Switzerland: Author.

BLINDED (2016). Details omitted for double-blind reviewing.

BLINDED (under final review). Details omitted for double-blind reviewing. 